All letters must be typed with double spacing and signed by all authors.

No letter should be more than 400 words.

For letters on scientific subjects we normally reserve our correspondence columns for those relating to issues discussed recently (within six weeks) in the BMF.

We do not routinely acknowledge letters. Please send a stamped addressed envelope if you would like an acknowledgment.

Because we receive many more letters than we can publish we may shorten those we do print, particularly when we receive several on the same subject.

\section{Expenditure on public services}

SIR, - Minerva bemoans the fact that the government's economic policy precludes adequate expenditure on health and other essential public services.' She will be pleased to know that the British government, with all other governments that are members of the World Health Organisation European region, has signed the recently published European Charter on Environment and Health. The charter, supported by the European Commission, commits the government to the principle that "the health of individuals and communities should take clear precedence over considerations of economy and trade": this is good news indeed for the health community. The charter, which constitutes a wide ranging commitment to developing and maintaining environmentally sound policies on health, can be obtained from the WHO regional office for Europe in Copenhagen.

ALEX SCOTT-SAMUEL

\section{Public Health Alliance.}

Liverpool L186JN

1 Minerva. Views. Br.Med f 1990;300:1024. (14 April.)

\section{Massive haemoptysis}

SIR,-The authors of your leader on massive haemoptysis recommend that the patient should lie head down on the side of bleeding to minimise accumulation of blood in the normal lung.

I have learnt that this should not be done, at least for bronchiectasis after repeated childhood pneumonia; indeed it is a recipe for making the haemoptysis "massive." The key is to keep the thorax upright for several hours by sitting as peacefully as possible on a fairly high chair so that the thighs are not pressed on the abdomen and the head is forward. Sometimes one may feel the bleeding stop directly or mav sense that it continues to ooze for a while. Presumably the procedure minimises the pressure of blood, which usually seems to be venous, at the bleeding point. Years ago Turner-Warwick described bronchopulmonary venous anastomoses in the bronchiectatic wall: the haemodynamics are not likely to be simple.

A temptation that must be resisted is to throw one's head back against the back of the chair in boredom or exasperation; this starts the bleeding again, I suppose by stretching the trachea. After a few hours one will feel the need to clear the bronchi and to assess progress. Stand up, bend forward with thorax horizontal, and take a few breaths, expiring deeply - coughing tends to dislodge clots. It should be possible to bring up enough of the sputum, blood, and clot to remove rhonchi, a useful sign of progress. When there is no sign of fresh blood, move to a bed with the thorax at an angle of about 30 degrees to the legs. Lying on the bleeding side, if it can be identified, is worth while. With luck, if one stays quiet and is always either upright or tilted, there may be no more bleeding. Exertion, too much coughing, and lying flat can dislodge the clot. On the next day one can move about cautiously. It is worth sleeping with the thorax raised for some days and raising the head of the bed permanently by $15 \mathrm{~cm}$.

Complete prevention seems impossible, and incidence is random. Obvious triggers have included walking up mountains, running for a bus, and grubbing up lilac suckers. But episodes have also occurred at a committee, while sitting quietly after dinner, and while lying in the bath. Broadly speaking, exertion, "hassle," infection, and air temperatures below $15^{\circ} \mathrm{C}$ seem to predispose to haemoptysis. With the procedure outlined one should not lose more than $30-40$ days a year through illness-less with a really quiet life. If there are only clots and staining one can go to a meeting or give a lecture, but it all drags on longer Episodes are commonest from September to March but can occur at any time of year.

The condition has its interest; from radiographic findings and the effects of cold I guess that it is an exercise in studying the pathophysiology of the bronchial surface around the physiological dead space. I suspect that these remarks may not help many, and that the condition is a sort of therapeutic fossil. My last pneumonia was in 1942, just in time for treatment with sulphadimidine. If the chemotherapy had developed later I would probably not have survived; if it had come earlier the damage would not have been done. Perhaps other conditions like diabetes, pernicious anaemia, and rheumatic fever have their fossils too.

W D M PATON

Oxford OX2 6XH

1 Jones DK, Davies RJ. Massive haemoptysis. Br Med f 1990;300 889-90. (7 April.)

SIR, - Massive haemoptysis is difficult to manage, and so we were interested in the editorial by Drs D Kevin Jones and Robert J Davies.' Preliminary results of a retrospective audit of bronchial artery embolisation at the Brompton and London Chest Hospitals leads us to question the statement that bronchial artery embolisation stops the bleeding (in the short term) in almost all patients. Major haemoptysis recurred within one week after 18 of 40 attempted bronchial artery embolisations to control acute major haemoptysis $(>100 \mathrm{ml})$ in 26 patients (the cause was cystic fibrosis in 16 patients, aspergilloma in six, bronchiectasis in three, and unknown in one).

The previously reported large studies of bronchial artery embolisation are from Brazil ${ }^{2}$ and Russia. ${ }^{3}$ In Brazil 70 of the 75 patients had tuberculosis and in Russia there were 306 patients with a wide range of chest diseases, including 118 with abscesses or pneumonia. The United Kingdom population of patients will be different, and our results suggest that bronchial artery embolisation has a significant failure rate. Our patients were not good candidates for surgery, and we do not know the efficacy in the United Kingdom of bronchial artery embolisation in patients with localised resectable disease, but we would consider emergency surgery instead of bronchial artery embolisation in this subgroup of patients if conservative management failed.

DAVID C CURRIE

COLM M PRENDERGAST MICHAEL C PEARSON DAVID M HANSELL

National Heart and Chest Hospitals, Brompton Hospital, London SW $36 \mathrm{HP}$

1 Jones DK, Davies RJ. Massive haemoptysis. Br Med $\mathcal{F}$ 1990;300: 889-90. (7 April.)

2 Rabkin JE, Astafjev VI, Gothman LM, Grigorjev YG. Transcatheter embolisation in the management of pulmonary haemorrhage. Radiology 1987:163:361-5.

3 Uflacker R, Kaemmerer A, Picon PD, et al. Bronchial artery embolisation in the management of haemoptysis: technical aspects and long-term results. Radiologv 1985;157:637-44.

SIR,_- "Massive haemoptysis" is an imprecise, almost emotive, term which tends to be overused as is arguably the case in your recent leading article. ' Expectoration of $200 \mathrm{ml}$ of blood over 24 hours can hardly be called "massive" haemoptysis; indeed, the authors have restricted their terms of reference largely to what would be described more accurately as considerable and persistent intrabronchial haemorrhage.

In that context they make several valid and important points, notably that asphyxiation is a much greater danger than blood loss, but the claim embodied in the subtitle that "medical management will usually arrest the bleeding" attributes to respiratory physicians powers which few, if any of them, possess. In exceptional circumstances haemorrhage can be arrested if an anaesthetist inserts an endobronchial Fogarty balloon catheter, if a radiologist embolises a bronchial artery, or if a surgeon resects a pulmonary lobe. All that most respiratory physicians can do is to keep the airway clear, correct hypoxaemia, and make good any appreciable blood loss until the bleeding ceases spontaneously, as it usually does.

Antituberculous treatment can hardly be expected to stem bleeding from a tuberculous cavity, and the chances of infused thrombin and fibrinogen or iced saline reaching the bleeding point in the face of a steady flow of blood are so remote as to render these procedures little more than facile gestures.

Most disturbing was the authors' preference 